\title{
Hepatocellular Carcinoma: Therapeutic Guidelines and Medical Treatment
}

\author{
Masatoshi Kudo ${ }^{a}$ Franco Trevisanib Ghassan K. Abou-Alfac,d \\ Lorenza Rimassa ${ }^{\mathrm{e}}$ \\ aDepartment of Gastroenterology and Hepatology, Kindai University Faculty of Medicine, Osaka- \\ Sayama, Japan, bSemeiotic Unit, Department of Medical and Surgical Sciences, Alma Mater Studio- \\ rum - University of Bologna, Bologna, Italy, cMemorial Sloan Kettering Cancer Center, dWeill Cornell \\ Medical College, N.Y., USA, eMedical Oncology and Hematology Unit, Humanitas Cancer Center, \\ Humanitas Clinical and Research Center, Milan, Italy
}

\section{Key Words}

Hepatocellular carcinoma $\cdot$ Practice guideline $\cdot$ Treatment $\cdot$ Treatment algorithm

\begin{abstract}
Western and Eastern perspectives on therapeutic guidelines for hepatocellular carcinoma (HCC) have many commonalities but may also differ in certain aspects, as described in this article. In view of the limited therapeutic options for advanced HCC, evidence-based therapies are few, and thus there is a dependence on consensus-based guidelines. This article focuses on the Italian Association for the Study of the Liver guidelines and the Japanese approaches to therapy, while drawing attention to certain controversies from other academic bodies where applicable and appropriate.

Copyright $\odot 2016$ S. Karger AG, Basel
\end{abstract}

\section{Therapeutic Guidelines: The Western Perspective}

In recent years several Western scientific associations have released and/or updated guidelines for the management of hepatocellular carcinoma (HCC) [1-3]. Refinements based on updated evidence and actual clinical practice have also been proposed [4]. The key points of Western guidelines are:

1. Surveillance. Six-monthly liver ultrasound examinations should be performed by experienced personnel. The measurement of alpha-fetoprotein combined with ultrasound is not 
indicated because it barely (6-8\%) increases the sensitivity, but significantly reduces the cost-effectiveness of surveillance. The target group comprises Child A/B cirrhotic patients, Child C patients listed for transplantation, non-cirrhotic hepatitis B surface antigen (HbsAg) carriers with active disease (or a family history of HCC), and hepatitis $\mathrm{C}$ virus (HCV)-infected patients with advanced fibrosis. There are different opinions regarding the use of alphafetoprotein, and the guidelines still lack recommendations or are unclear with respect to patients with non-alcoholic fatty liver disease, the population that has experienced the highest increase in HCC incidence in the Western Hemisphere.

2. Diagnosis. When a new nodule is detected by ultrasound in a cirrhotic liver, the recall policy is driven by the nodule size: for nodules $<1 \mathrm{~cm}, 3$-monthly ultrasound surveillance is recommended; for nodules $>1 \mathrm{~cm}$, HCC diagnosis requires detection of the typical vascular hallmarks (wash-in in the arterial phase and wash-out in the portal/delayed phases) by one radiological technique (computed tomography [CT] or magnetic resonance imaging [MRI]) at specialist centers [1-3] or by two radiological techniques at non-specialist centers [2]. The Italian Association for the Study of the Liver (AISF) also includes contrast-enhanced ultrasound among the diagnostic tools that are able to characterize nodules [4]. A "panoramic" imaging technique (CT or MRI) remains mandatory to assess the global tumoral burden for all guidelines. MRI has the highest sensitivity for detecting the typical vascular pattern in HCC $<2 \mathrm{~cm}$ and is superior for the detection of hypovascular HCC when hepatocyte-specific contrast agents and post-vascular phase assessments are used. A biopsy is required if atypical features are evident on imaging and in noncirrhotic patients. A negative biopsy does not rule out malignancy, and 3-monthly ultrasound examinations are recommended. It is important to note that these diagnostic guidelines and tools are limited in scope to the screening population described herein.

3. Staging. All Western hepatology guidelines have endorsed the Balcelona Clinic Liver Cancer (BCLC) staging system for classification of patients into five prognostic strata according to their cancer burden, liver function, and performance status (PS). This system also proposes, in an evidence-based way, the standard of care treatment for each stage. However, because PS 1 does not preclude access to any available treatments for HCC, the Italian AISF has modified the BCLC therapeutic algorithm, and does not consider PS 1 a condition per se sufficient to up-grade a patient from earlier stages to advanced stages, for which only systemic therapy with sorafenib is recommended (AISF-BCLC staging system). Oncology experts differ in their opinions regarding the BCLC staging system, and some of them favor more precise systems [e.g., the Cancer of the Liver Italian Program, among others] for assessing advanced disease [5].

4. Treatment. Despite the BCLC indications, most associations (including AISF) have endorsed a more patient-tailored approach that is based on the multidisciplinary evaluation of each case and includes alternative first-line options [4]. Some key recommendations are (a) the presence of portal hypertension, hyperbilirubinemia, and multinodularity do not preclude hepatic resection, although this option must be accurately weighed against the risk of post-operative decompensation; (b) according to "transplant benefit" policy, liver transplantation may be considered even in patients slightly exceeding the Milan criteria as part of "expanded criteria" or "down-staging" protocols; (c) transarterial chemoembolization (TACE) should be adopted as the first-line therapy for intermediate (BCLC stage B) patients if they are not amenable to curative treatments (surgery or ablation); (d) the presence of segmental portal invasion is not a contraindication to TACE, although systemic therapy has shown possible benefits for these patients as a part of controlled studies; (e) the absence of an objective (complete or partial) response in treated lesions after two courses of TACE is considered a treatment failure, and sorafenib should be started (fig. 1); (f) combined loco-regional therapies (TACE plus ablation) offer maximum flexibility, allowing a nodule-by-nodule tailored 


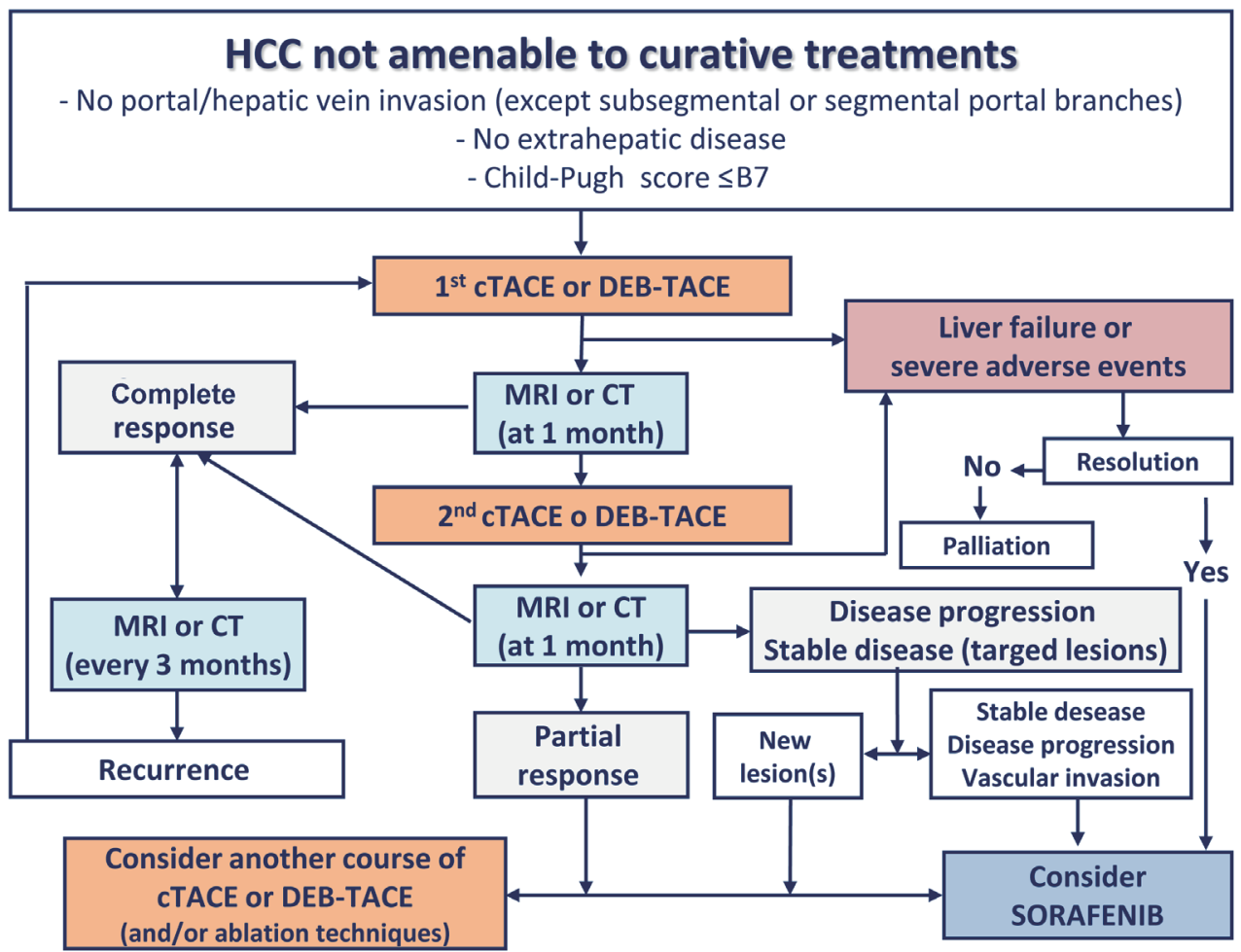

\section{Footnotes}

The tumor response should be assessed with the modified Response Evaluation Criteria In Solid Tumor (mRECIST).

After conventional TACE (CTACE), MRI is preferable since its sensitivity in detecting viable tumor tissue is not affected by Lipiodol staining.

Fig. 1. Treatment algorithm for patients undergoing TACE, according to the recommendation of AISF. The flowchart is valid for any session of TACE. For conventional TACE (CTACE), MRI is preferable since lipiodol uptake causes beam hardening artifacts on CT that mask residual tumor tissue. The response to treatment is assessed by the modified Response Evaluation Criteria in Solid Tumor (mRECIST). Reproduced with permission from Bolondi N, et al. [4]

approach. Therefore, in non-surgical cases, a combined/sequential treatment should be considered for multinodular disease treated with TACE and for nodules $>3 \mathrm{~cm}$ undergoing ablation. It is important to note that other guidelines, e.g., those of the National Comprehensive Cancer Network, are more cautious in these regards: they continue to limit transplantation to patients meeting published criteria and refrain from recommending combined local and systemic therapies, citing a lack of supporting data.

\section{Therapeutic Guidelines: The Eastern Perspective}

\section{Evidence-Based Treatment Algorithm}

The original Japan Society of Hepatology (JSH) HCC guidelines and all later updates contain an evidence-based treatment algorithm that is simple and easy to memorize. The algorithm includes three factors: (i) the degree of liver damage, (ii) the number of tumors, and (iii) the tumor diameter (fig. 2). The recommended treatment options can be narrowed down 


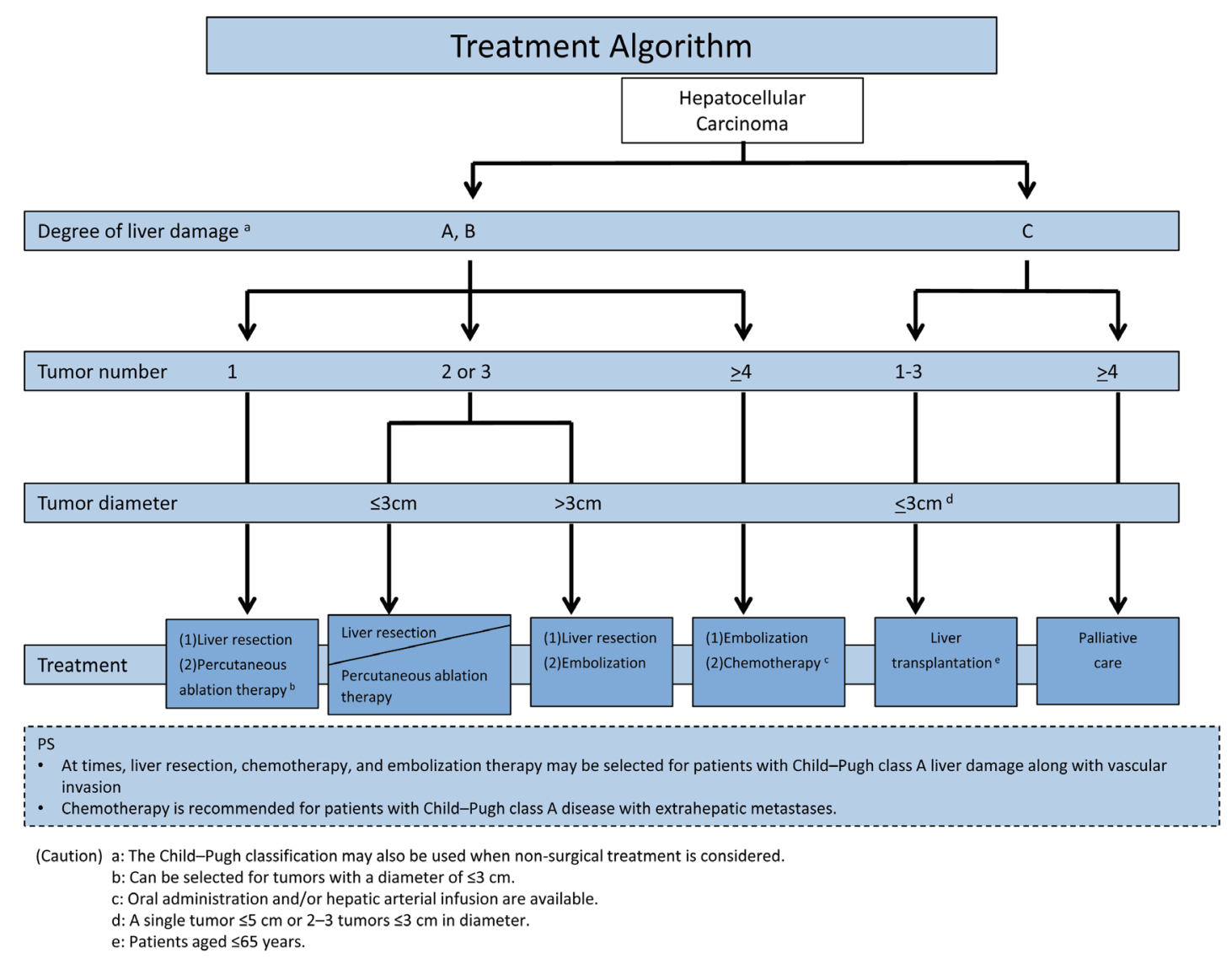

Fig. 2. JSH Evidence-based Treatment Algorithm. Modified with permission from Kokudo N, et al. [40]

to one or two by referring to this algorithm. The most recent version of the evidence-based treatment algorithm can be summarized as follows:

1. The order of the recommendations for surgical resection and percutaneous radiofrequency ablation (RFA) has been clarified. Based on the results of large nationwide cohort studies conducted by the Liver Cancer Study Group of Japan (LCSGJ) [6, 7], surgical resection is set as the first therapeutic choice for HCC patients with a single tumor with liver damage of grade A or B. If the tumor is smaller than $3 \mathrm{~cm}$ in cases meeting the above conditions, RFA is recommended as the second choice. During the target period for the current revision (2007-2011), there were three randomized controlled trials (RCTs) comparing surgery and RFA [8-10]. However, the results of these RCTs were not reflected in the treatment algorithm because the trials had several problems, as described elsewhere [11]. For a patient with liver damage of grade A or B and two or three tumors smaller than $3 \mathrm{~cm}$, either surgical resection or RFA is recommended with no priority, based on a Japanese cohort study [6, 7].

2. Based on the results of the phase III clinical trial of sorafenib versus placebo in patients with advanced HCC (the SHARP study) [12], the multi-tyrosine kinase inhibitor sorafenib is suggested in the third version of the treatment algorithm. In patients with liver damage of grade A or B and four or more tumors confined to the liver, systemic chemotherapy, including molecular-targeted agents and hepatic arterial infusion chemotherapy (HAIC), is the second recommended treatment after TACE.

3. Since the first JSH-HCC guidelines, the assessment of liver damage covered five factors, including the indocyanine green (ICG) test, and has been used as an indicator of liver func- 
tion. Although the ICG test is considered indispensable for surgical decision making in Japan, it is not routinely performed before non-surgical treatments such as RFA and TACE in current daily practice in Japan. The Child-Pugh classification serves as a substitute liver function grading system only before non-surgical treatments.

\section{Consensus-Based Treatment Algorithm}

Although sorafenib is recommended for patients with segmental portal vein invasion or portal invasion at the first portal branch (Vp1-3), the JSH-LCSGJ algorithm reflects the consensus that it is not recommended for patients with portal invasion at the main portal branch (Vp4) because of the risk of hepatic failure. However, HAIC is still recommended for patients with Vp4, and therefore recommendations regarding HAIC were left unchanged [13]. Moreover, because locoregional therapy for Child-Pugh C patients is now widely used, and many studies have reported its survival benefits, it is now described as a "well accepted treatment" rather than an "experimental treatment" in the revised algorithm (fig. 3) [14].

\section{Definition of TACE Failure/Refractoriness}

In the 2010 version of the JSH consensus-based treatment algorithm [15], TACE failure/ refractoriness was defined assuming the use of superselective lipiodol TACE-which has been widely used worldwide, and particularly in Japan - and areas with lipiodol deposition were considered to be necrotic. However, this concept is not well accepted internationally [16]. Furthermore, following the approval in Japan in February 2014 of embolic drug-eluting beads (DEBs) that do not use lipiodol, the phrase needed to be changed from "lipiodol deposition" to "necrotic lesion or viable lesion." Accordingly, the section was revised to define TACE failure as an ineffective response after two or more consecutive TACE procedures as evaluated by CT or MRI after 1-3 months, even after chemotherapeutic agents have been changed and/or the feeding artery reanalyzed. Moreover, the appearance of new lesions in the liver in addition to those lesions recorded at the previous TACE procedure (other than the nodule being treated) was added to the definition of TACE failure/refractoriness. Following discussion of other issues related to continuous elevation of tumor markers, vascular invasion, and extrahepatic spread, descriptions similar to those in the previous version were approved (table 1). The revisions to these TACE failure definitions were approved by more than $85 \%$ of HCC experts.

\section{Controversies Regarding Medical Treatment}

The advent of sorafenib as a standard of care for advanced HCC [12] settled the basic question of how to treat that condition, but raised many other questions, the most contemporary of which concern the use of sorafenib in more cirrhotic settings and the influence, if any, of the etiology of HCC on outcomes.

Sorafenib was first approved by the United States Food and Drug Administration without any reference to the degree of cirrhosis [17] because of the "paucity of treatment options and variability in CP Scoring" [18]. In the phase II trial evaluating sorafenib in patients with advanced HCC, of 137 patients, 38 had Child-Pugh B cirrhosis [19]. In a retrospective analysis, it was found that the median duration of therapy was 4 months for Child-Pugh A patients and 1.8 months for Child-Pugh B patients, with a median overall survival (OS) of 9.5 months versus 3.2 months, respectively [20]. However, the fact that similar pharmacokinetics were evident in the two groups adds to the controversy. On the other hand, a phase I study evaluating sorafenib in 150 patients with organ dysfunction (including 17 patients with HCC) indicated that treatment with sorafenib was associated with dose-limiting elevations in serum biliru- 


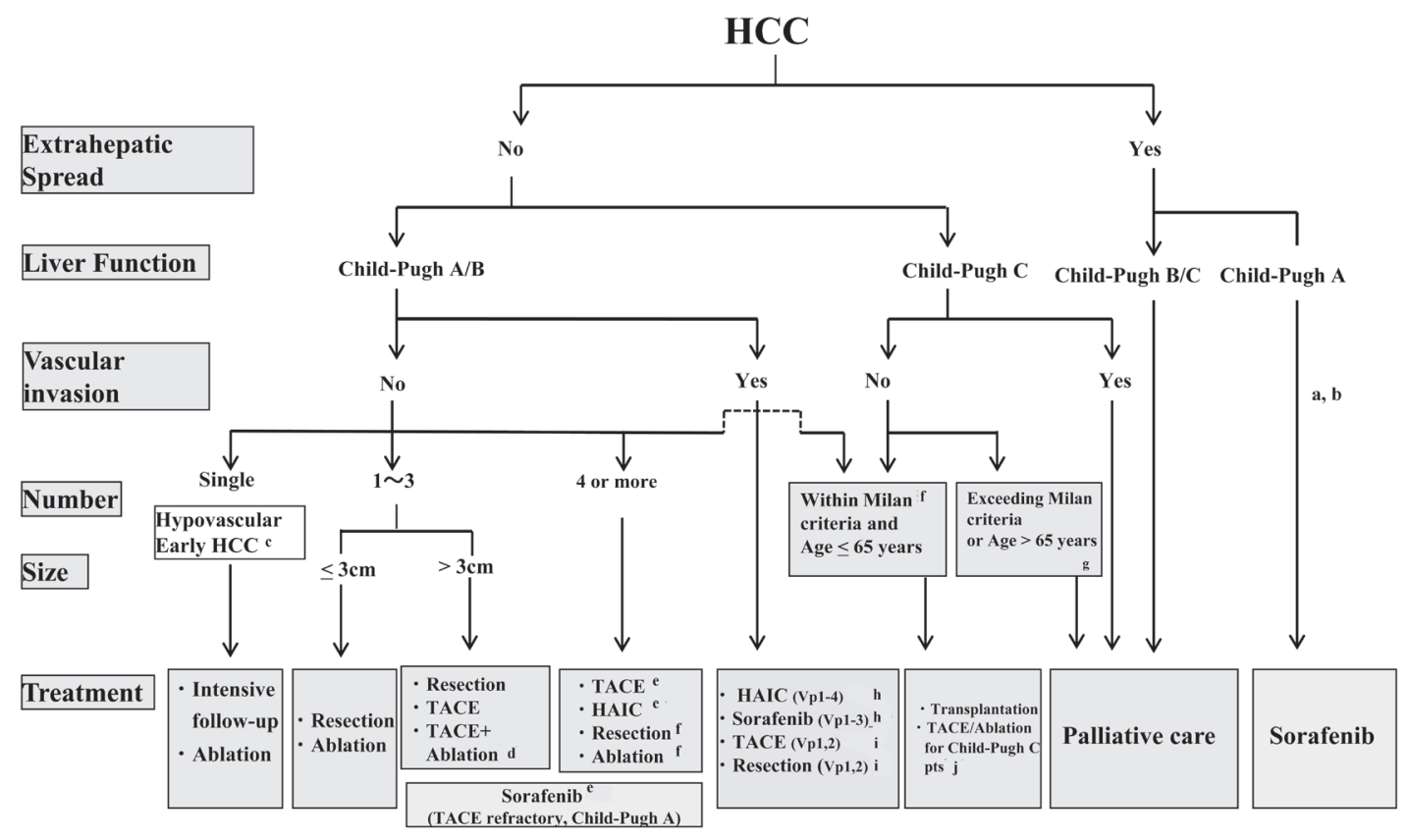

Fig. 3. JSH-LCSGJ Consensus-based Treatment Algorithm for HCC as revised in 2014. Reproduced with permission from Kudo M, et al. [14]

${ }^{a}$ Treatment should be performed as if extrahepatic spread is negative, when extrahepatic spread is not regarded as a prognostic factor. ${ }^{b}$ Sorafenib is the first choice of treatment in this setting as a standard of care. ${ }^{C}$ Intensive follow-up observation is recommended for hypovascular nodules by the Japanese Evidence-Based Clinical Practice Guidelines. However, local ablation therapy is frequently performed in the following cases: (1) when the nodule is diagnosed pathologically as early HCC, (2) when the nodules show decreased uptake on hepatocyte phase Gd-EOB-MRI, (3) when the nodules show decreased portal flow by CTAP or (4) decreased uptake is shown on the Kupffer phase of Sonazoid-enhanced US, since these nodules are known to frequently progress to typical hypervascular HCC. ${ }^{\mathrm{d}}$ Even for HCC nodules exceeding $3 \mathrm{~cm}$ in diameter, combination therapy of TACE and ablation is frequently performed when resection

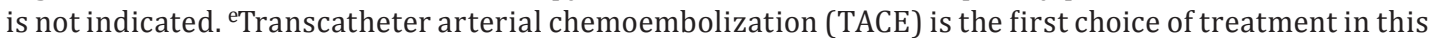
setting. Hepatic arterial infusion chemotherapy (HAIC) using an implanted port is also recommended for TACE-refractory patients. The regimen for this treatment is usually low-dose FP (5FU+CDDP) or intraarterial 5FU infusion combined with systemic interferon therapy. Sorafenib is also a treatment of choice for TACE-refractory patients with Child-Pugh A liver function. ${ }^{\mathrm{f}}$ Resection is sometimes performed even when more than 4 nodules are present. Furthermore, ablation is sometimes performed in combination with TACE. gMilan criteria: Tumor size $\leq 3 \mathrm{~cm}$ and tumor number $\leq 3$; or solitary tumor $\leq 5 \mathrm{~cm}$. Even when liver function is good (Child-Pugh A/B), transplantation is sometimes considered for frequently recurring HCC

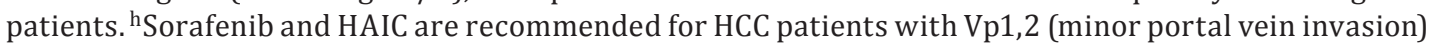
or Vp3 (portal invasion at the 1st portal branch). Sorafenib is not recommended for HCC patients with Vp4 (portal invasion at the main portal branch), whereas HAIC is recommended for such patients with

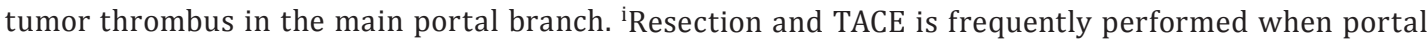
invasion is minimal, such as Vp1 (portal invasion at the 3rd or more peripheral portal branch) or Vp2

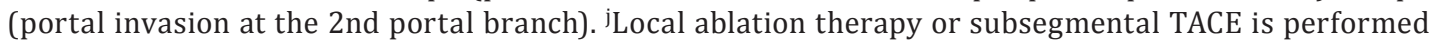
even for Child-Pugh C patients when transplantation is not indicated and there is no hepatic encephalopathy, no uncontrollable ascites, and a low bilirubin level $(<3.0 \mathrm{mg} / \mathrm{dl})$. Although it is a well-accepted treatment in the routine clinical setting, there is no evidence of a survival benefit in Child-Pugh $\mathrm{C}$ patients. A prospective study is necessary to clarify this issue. Even in Child-Pugh A/B patients, transplantation is sometimes performed for relatively young patients with frequently or early recurring HCC after curative treatments.

bin concentration in patients with more advanced Child-Pugh scores [21]. Based on these observations, the authors recommended a dosing schedule for sorafenib based on bilirubin 
Table 1. Definition of TACE failure/refractoriness (LCSGJ)

\section{Intrahepatic lesion}

I. Two or more consecutive ineffective responses within the treated tumors (viable lesion $>50 \%$ ) even after changing the chemotherapeutic agents and/or reanalysis of the feeding artery. The ineffective responses are determined by response evaluation CT/MRI images taken 1-3 months following adequately performed selective TACE

II. Two or more consecutive progressions in the liver (tumor numbers even increase compared to the tumor numbers before the previous TACE procedure) even after changing the chemotherapeutic agents and/or reanalysis of the feeding artery. The progressions are detected on response evaluation CT/MRI images taken 1-3 months following adequately performed selective TACE

\section{Tumor marker}

Continuous elevation of tumor markers right after TACE even though transient minor reduction is observed.

3. Appearance of vascular invasion

4. Appearance of extrahepatic spread

levels. This concept remains controversial, with a post-marketing study showing similar overall safety profiles and dosing strategies in the different Child-Pugh groups [22].

Multiple studies have shown that patients with Hepatitis B Virus (HBV)-related HCC who were treated with sorafenib had a modest prolongation in median OSin contrast to HCV-related HCC patients who had a substantial improvement in survival almost double that of the former group [23-25]. Within the limitations of the retrospective nature of most of these data, an etiology-dependent genomic difference in HCC was theorized. CTNNB1 mutations are more commonly observed in HCV-related HCC than in HBV-related HCC and are associated with a specific WNT gene expression profile [26]. Sorafenib has been shown to interfere with WNT signaling output, leading to HCC growth suppression in preclinical models. Another explanation is the induction of sorafenib target CRAF by HCV core protein [27]. Although more exploration is certainly required, it should be emphasized that the utility of sorafenib is not undermined by this observation, and sorafenib remains an effective and life-prolonging therapy for HCC, irrespective of etiologic factors. Nonetheless the advent of next-generation sequencing of the somatic mutations in HCC will add to the controversy and may guide the next wave of clinical trials as the genetic heterogeneity and complexity of HCC become more evident and increasingly recognized.

\section{Is It Time for a Second-Line Systemic Treatment?}

Sorafenib is the only approved systemic agent for the treatment of advanced HCC and there is a great unmet need for new, effective therapies for this condition. Although the clinical and molecular diversity of HCC poses a challenge for drug developers, several novel targets are undergoing evaluation, most notably hepatocyte growth factor receptor (MET).

Table 2 shows the recently published multicenter, double-blind, randomized, placebocontrolled phase III trials of potential second-line HCC treatments [28-30]. These trials evaluated two small molecules, brivanib and everolimus, and a monoclonal antibody, ramucirumab, and all failed to reach their endpoints. Interestingly, the REACH trial identified a pre-defined subpopulation, i.e., patients with high baseline alpha-fetoprotein values, who benefited from treatment with ramucirumab [31].

However, some important lessons were learned from these trials, and our understanding of liver cancer is evolving. Until recently, it was not clear how long patients well enough 
Table 2. Second-line phase III trials in advanced HCC

\begin{tabular}{|c|c|c|c|}
\hline Trial & $\begin{array}{l}\text { Principle target of } \\
\text { experimental drug }\end{array}$ & No. of patients & Median OS \\
\hline $\begin{array}{l}\text { Brivanib versus placebo } \\
\text { (BRISK-PS)[28] }\end{array}$ & VEGFR, FGFR & 395 & $\begin{array}{l}9.4 \text { versus } 8.2 \text { months } \\
\text { HR } 0.89(0.69-1.15), p=0.33\end{array}$ \\
\hline $\begin{array}{l}\text { Everolimus versus placebo } \\
\text { (EVOLVE-1)[29] }\end{array}$ & mTOR & 546 & $\begin{array}{l}7.6 \text { versus } 7.3 \text { months } \\
\text { HR } 1.05(0.86-1.27), p=0.68\end{array}$ \\
\hline $\begin{array}{l}\text { Ramucirumab versus placebo } \\
(\mathrm{REACH})[30]\end{array}$ & VEGFR2 & 565 & $\begin{array}{l}9.2 \text { versus } 7.6 \text { months } \\
\text { HR } 0.87(0.72-1.05), p=0.14\end{array}$ \\
\hline
\end{tabular}

VEGFR=vascular endothelial growth factor receptor; FGFR=fibroblast growth factor receptor; $\mathrm{HR}=$ hazard ratio; $\mathrm{mTOR}=$ mechanistic target of rapamycin.

to participate in subsequent clinical trials survived after progression on sorafenib, making it difficult to interpret single-arm phase II trials. Now, it has been shown that, compared with patients ineligible for second-line trials, potentially eligible patients have a longer OS (median: 7.8-8.6 months), and this sets a new potential benchmark for assessing single-arm phase II studies [32]. Moreover, the high failure rate of HCC phase III trials results from the peculiar characteristics of this disease, such as the high rate of toxicity related to the underlying liver dysfunction, the challenges of discerning signals of efficacy from nonrandomized phase II data (because of uninformative surrogate endpoints and prognostic heterogeneity within clinical and biologic subsets), the imbalances in disease (liver-only versus metastatic spread), and patient characteristics (Child-Pugh class, cause of cirrhosis, ethnicity).

Taking a step back to early-phase trials, the development of the oral MET-inhibitor tivantinib may be taken as an informative example. First, two phase Ib studies in HCC [33, 34] and then a randomized placebo-controlled phase II study with extensive biomarker analysis were conducted $[35,36]$. This phase II study defined MET expression as a prognostic factor for second-line treatment. The study reached its primary endpoint of time-to-progression in the overall population and reached the predefined secondary efficacy endpoints in MET-high patients, showing that high MET-expression identifies a group of patients who benefit most. This strategy for patient selection is being applied in the ongoing METIV-HCC phase III trial [37].

Metabolomics as single agent did not fare any better. In a randomized phase III study of ADI-PEG 20 arginine deaminase versus placebo, there was no difference in survival inbetween the two arms [38]. Future ADI-PEG 20 therapies will be based on combinatorial studies that would help enhance the activity of the drug.

Despite the discouraging outocmes of most recent studies, the latest have shown a more promising outcome. In a phase III trial, patients with advanced HCC who progressed on soarfenib were randomized to regorafenib, a similar mutli-tyrosine kinase versus placebo. The study showed an improvement in survival to 10.6 months versus 7.9 in favor of regorafenib. Further dissection of this positive outcome may be required considering the rather unrestrictive short use of prior sorafenib, the requirement of prior sorafenib tolerance, and the randomization up to 10 weeks after sorafenib failure which all may suggest a selection bias for the population [39].

In conclusion, to develop an effective second-line systemic treatment for advanced HCC, we need to better understand the clinical and biologic factors that affect prognosis and response so as to facilitate stratification and biomarker enrichment strategies. Additionally, we need to change our approach to the development of systemic therapies. In fact, we can no longer proceed with phase III trials of experimental drugs unless they show statistically significantly advantages in randomized phase II trials or clinically meaningful benefits in 
nonrandomized phase II studies with an adequate number of homogeneous patients. Furthermore, the collection of biologic samples should become part of routine clinical practice to help identify and validate prognostic and predictive biomarkers (e.g., MET).

\section{Disclosure Statement}

Masatoshi Kudo

Lecturer: Bayer, Kowa, Taiho

Grants: Chugai, Otsuka, Takeda, Taiho, Sumitomo Dainippon, Daiichi Sankyo, MSD, Eisai

Franco Trevisani

Lectures, grants and advisory role: Bayer

Ghassan K. Abou-Alfa

Research: Abbott Laboratories, Amgen, Bayer, CASI, Celgene, Eli Lilly and Company/Imclone, Exelixis, Genentech, Immunomedics, Incyte, Momenta Pharmaceuticals, Myriad Genetics, Novartis, OncoMed Pharmaceuticals, Polaris Pharmaceuticals, Roche, and Vicus Therapeutics

Consulting: Aduro Biotech, Array, Astellas Pharma US, BioAlliance, Boston Scientific, Boston Therapeutics, BMS, CASI, Celgene, Cipla, Eli Lilly and Company, EMD Sorono, Gilead, IntegraGen, Medergy, MedImmune, Merrimack, Momenta, Novartis, Onxeo, Pharmacyclics, Sanofi-aventis, Silenseed, Sillajen, and Vicus Therapeutics.

Lorenza Rimassa

Consulting or advisory role: Lilly, Merck Serono, Bayer

Travel grants: ArQule

Other (Educational meeting speaker): Amgen

\section{References}

1 Bruix J, Sherman M, American Association for the Study of Liver Diseases: Management of hepatocellular carcinoma: an update. Hepatology 2011;53:1020-1022.

2 Llovet JM, Ducreux M, et al, European Association for the Study of the Liver, European Organisation for Research and Treatment of Cancer: EASL-EORTC clinical practice guidelines: management of hepatocellular carcinoma. J Hepatol 2012;56:908-943.

3 Verslype C, Rosmorduc O, Rougier P, ESMO Guidelines Working Group: Hepatocellular carcinoma: ESMO-ESDO Clinical Practice Guidelines for diagnosis, treatment and follow-up. Ann Oncol 2012;23(Suppl 7):vii41-vii48.

4 Bolondi L, Cillo U, Colombo M, Craxì A, Farinati F, Giannini EG, Golfieri R, Levrero M, Pinna AD, Piscaglia F, Raimondo G, Trevisani F, Bruno R, Caraceni P, Ciancio A, Coco B, Fraquelli M, Rendina M, Squadrito G, Toniutto P, Italian Association for the Study of the Liver (AISF), AISF Expert Panel, AISF Coordinating Committee: Position paper of the Italian Association for the Study of the Liver (AISF): the multidisciplinary clinical approach to hepatocellular carcinoma. Dig Liver Dis 2013;45:712-723.

5 Huitzil-Melendez FD, Capanu M, O’Reilly EM, Duffy A, Gansukh B, Saltz LL, Abou-Alfa GK: Advanced hepatocellular carcinoma: which staging systems best predict prognosis? J Clin Oncol 2010;28:2889-2895.

6 Hasegawa K, Makuuchi M, Takayama T, Kokudo N, Arii S, Okazaki M, Okita K, Omata M, Kudo M, Kojiro M, Nakanuma Y, Takayasu K, Monden M, Matsuyama Y, Ikai I: Surgical resection vs. percutaneous ablation for hepatocellular carcinoma: a preliminary report of the Japanese nationwide survey. J Hepatol 2008;49:589594.

7 Hasegawa K, Kokudo N, Makuuchi M, Izumi N, Ichida T, Kudo M, Ku Y, Sakamoto M, Nakashima O, Matsui O, Matsuyama Y: Comparison of resection and ablation for hepatocellular carcinoma: a cohort study based on a Japanese nationwide survey. J Hepatol 2013;58:724-729.

8 Huang GT, Lee PH, Tsang YM, Lai MY, Yang PM, Hu RH, Chen PJ, Kao JH, Sheu JC, Lee CZ, Chen DS: Percutaneous ethanol injection versus surgical resection for the treatment of small hepatocellular carcinoma: a prospective study. Ann Surg 2005;242:36-42.

9 Chen MS, Li JQ, Zheng Y, Guo RP, Liang HH, Zhang YQ, Lin XJ, Lau WY: A prospective randomized trial comparing percutaneous local ablative therapy and partial hepatectomy for small hepatocellular carcinoma. Ann Surg 2006;243:321-328.

10 Huang J, Yan L, Cheng Z, Wu H, Du L, Wang J, Xu Y, Zeng Y: A randomized trial comparing radiofrequency ablation and surgical resection for HCC conforming to the Milan criteria. Ann Surg 2010;252:903-912.

11 Hasegawa K, Kokudo N, Makuuchi M: Surgery or ablation for hepatocellular carcinoma? Ann Surg 2008;247:557-558. 
12 Llovet JM, Ricci S, Mazzaferro V, Hilgard P, Gane E, Blanc JF, de Oliveira AC, Santoro A, Raoul JL, Forner A, Schwartz M, Porta C, Zeuzem S, Bolondi L, Greten TF, Galle PR, Seitz JF, Borbath I, Häussinger D, Giannaris T, Shan M, Moscovici M, Voliotis D, Bruix J, SHARP Investigators Study Group: Sorafenib in advanced hepatocellular carcinoma. N Engl J Med 2008;359:378-390.

13 Kudo M: Treatment of advanced hepatocellular carcinoma with emphasis on hepatic arterial infusion chemotherapy and molecular targeted therapy. Liver Cancer 2012;1:62-70.

14 Kudo M, Matsui O, Izumi N, Iijima H, Kadoya M, Imai Y, Okusaka T, Miyayama S, Tsuchiya K, Ueshima K, Hiraoka A, Ikeda M, Ogasawara S, Yamashita T, Minami T, Yamakado K, Liver Cancer Study Group of Japan: JSH consensus-based clinical practice guidelines for the management of hepatocellular carcinoma: 2014 update by the Liver Cancer Study Group of Japan. Liver Cancer 2014;3:458-468.

15 Kudo M, Izumi N, Kokudo N, Matsui O, Sakamoto M, Nakashima O, Kojiro M, Makuuchi M, HCC Expert Panel of Japan Society of Hepatology: Management of hepatocellular carcinoma in Japan: Consensus-Based Clinical Practice Guidelines proposed by the Japan Society of Hepatology (JSH) 2010 updated version. Dig Dis 2011;29:339-364.

16 Raoul JL, Gilabert M, Piana G: How to define transarterial chemoembolization failure or refractoriness: a European perspective. Liver Cancer 2014;3:119-124.

17 U.S. Food and Drug Administration. FDA approves sorafenib (nexavar) for the treatment of unresectable hepatocellular carcinoma. Available at: http://www.fda.gov/cder/Offices/OODP/whatsnew/sorafenib. htm. Accessed October 3, 2015.

18 Kane RC, Farrell AT, Madabushi R, Booth B, Chattopadhyay S, Sridhara R, Justice R, Pazdur R: Sorafenib for the treatment of unresectable hepatocellular carcinoma. Oncologist 2009;14:95-100.

19 Abou-Alfa GK, Schwartz L, Ricci S, Amadori D, Santoro A, Figer A, De Greve J, Douillard JY, Lathia C, Schwartz B, Taylor I, Moscovici M, Saltz LB: Phase II study of sorafenib in patients with advanced hepatocellular carcinoma. J Clin Oncol 2006;24:4293-4300.

20 Abou-Alfa GK, Amadori D, Santoro A, Figer A, De Greve J, Lathia C, Voliotis D, Anderson S, Moscovici M, Ricci S: Safety and efficacy of sorafenib in patients with hepatocellular carcinoma (HCC) and Child-Pugh A versus B cirrhosis. Gastrointest Cancer Res 2011;4:40-44.

21 Miller AA, Murry DJ, Owzar K, Hollis DR, Kennedy EB, Abou-Alfa G, Desai A, Hwang J, Villalona-Calero MA, Dees EC, Lewis LD, Fakih MG, Edelman MJ, Millard F, Frank RC, Hohl RJ, Ratain MJ: Phase I and pharmacokinetic study of sorafenib in patients with hepatic or renal dysfunction: CALGB 60301. J Clin Oncol 2009;27:1800-1805.

22 Lencioni R, Kudo M, Ye SL, Bronowicki JP, Chen XP, Dagher L, Furuse J, Geschwind JF, de Guevara LL, Papandreou C, Takayama T, Yoon SK, Nakajima K, Lehr R, Heldner S, Sanyal AJ: GIDEON (Global Investigation of therapeutic DEcisions in hepatocellular carcinoma and Of its treatment with sorafeNib): second interim analysis. Int J Clin Pract 2014;68:609-617.

23 Bruix J, Raoul JL, Sherman M, Mazzaferro V, Bolondi L, Craxi A, Galle PR, Santoro A, Beaugrand M, Sangiovanni A, Porta C, Gerken G, Marrero JA, Nadel A, Shan M, Moscovici M, Voliotis D, Llovet JM: Efficacy and safety of sorafenib in patients with advanced hepatocellular carcinoma: subanalyses of a phase III trial. J Hepatol 2012;57:821-829.

24 Cheng AL, Kang YK, Lin DY, Park JW, Kudo M, Qin S, Chung HC, Song X, Xu J, Poggi G, Omata M, Pitman Lowenthal S, Lanzalone S, Yang L, Lechuga MJ, Raymond E: Sunitinib versus sorafenib in advanced hepatocellular cancer: results of a randomized phase III trial. J Clin Oncol 2013;31:4067-4075.

25 Abou-Alfa GK: Selection of patients with hepatocellular carcinoma for sorafenib. J Natl Compr Canc Netw 2009;7:397-403.

26 Lachenmayer A, Alsinet C, Savic R, Cabellos L, Toffanin S, Hoshida Y, Villanueva A, Minguez B, Newell P, Tsai HW, Barretina J, Thung S, Ward SC, Bruix J, Mazzaferro V, Schwartz M, Friedman SL, Llovet JM: Wntpathway activation in two molecular classes of hepatocellular carcinoma and experimental modulation by sorafenib. Clin Cancer Res 2012;18:4997-5007.

27 Giambartolomei S, Covone F, Levrero M, Balsano C: Sustained activation of the Raf/MEK/Erk pathway in response to EGF in stable cell lines expressing the hepatitis $\mathrm{C}$ virus (HCV) core protein. Oncogene 2001;20:2606-2610.

28 Llovet JM, Decaens T, Raoul JL, Boucher E, Kudo M, Chang C, Kang YK, Assenat E, Lim HY, Boige V, Mathurin P, Fartoux L, Lin DY, Bruix J, Poon RT, Sherman M, Blanc JF, Finn RS, Tak WY, Chao Y, Ezzeddine R, Liu D, Walters I, Park JW: Brivanib in patients with advanced hepatocellular carcinoma who were intolerant to sorafenib or for whom sorafenib failed: results from the randomized phase III BRISK-PS study. J Clin Oncol 2013;31:3509-3516.

29 Zhu AX, Kudo M, Assenat E, Cattan S, Kang YK, Lim HY, Poon RT, Blanc JF, Vogel A, Chen CL, Dorval E, PeckRadosavljevic M, Santoro A, Daniele B, Furuse J, Jappe A, Perraud K, Anak O, Sellami DB, Chen LT: Effect of everolimus on survival in advanced hepatocellular carcinoma after failure of sorafenib: the EVOLVE-1 randomized clinical trial. JAMA 2014;312:57-67.

30 Zhu AX, Park JO, Ryoo BY, Yen CJ, Poon R, Pastorelli D, Blanc JF, Chung HC, Baron AD, Pfiffer TE, Okusaka T, Kubackova K, Trojan J, Sastre J, Chau I, Chang SC, Abada PB, Yang L, Schwartz JD, Kudo M, REACH Trial Investigators: Ramucirumab versus placebo as second-line treatment in patients with advanced hepatocellular carcinoma following first-line therapy with sorafenib (REACH): a randomised, double-blind, multicentre, phase 3 trial. Lancet Oncol 2015;16:859-870.

31 Zhu AX, Ryoo BY, Yen CJ, et al.: Ramucirumab (RAM) as second-line treatment in patients (pts) with advanced hepatocellular carcinoma (HCC): Analysis of patients with elevated $\alpha$-fetoprotein (AFP) from the randomized phase III reach study. J Clin Oncol 33, 2015 (suppl 3; abstr 232). 
32 Shao YY, Wu CH, Lu LC, Chan SY, Ma YY, Yen FC, Hsu CH, Cheng AL: Prognosis of patients with advanced hepatocellular carcinoma who failed first-line systemic therapy. J Hepatol 2014;60:313-318.

33 Santoro A, Simonelli M, Rodriguez-Lope C, Zucali P, Camacho LH, Granito A, Senzer N, Rimassa L, Abbadessa G, Schwartz B, Lamar M, Savage RE, Bruix J: A Phase-1b study of tivantinib (ARQ 197) in adult patients with hepatocellular carcinoma and cirrhosis. Br J Cancer 2013;108:21-24.

34 Puzanov I, Sosman J, Santoro A, Saif MW, Goff L, Dy GK, Zucali P, Means-Powell JA, Ma WW, Simonelli M, Martell R, Chai F, Lamar M, Savage RE, Schwartz B, Adjei AA: Phase 1 trial of tivantinib in combination with sorafenib in adult patients with advanced solid tumors. Invest New Drugs 2015;33:159-168.

35 Santoro A, Rimassa L, Borbath I, Daniele B, Salvagni S, Van Laethem JL, Van Vlierberghe H, Trojan J, Kolligs FT, Weiss A, Miles S, Gasbarrini A, Lencioni M, Cicalese L, Sherman M, Gridelli C, Buggisch P, Gerken G, Schmid RM, Boni C, Personeni N, Hassoun Z, Abbadessa G, Schwartz B, Von Roemeling R, Lamar ME, Chen Y, Porta C: Tivantinib for second-line treatment of advanced hepatocellular carcinoma: a randomised, placebo-controlled phase 2 study. Lancet Oncol 2013;14:55-63.

36 Rimassa L, Abbadessa G, Personeni N, Porta C, Borbath I, Daniele B, Van Laethem JL, Van Vlierberghe H, Trojan J, De Toni E, Peck-Radosavljevic M, Finn RS, Raoul JL, He AR, Lamar M, Wang Y, Von Roemeling RW, Schwartz BE, Bruix J, Santoro A: Tumor and plasma biomarker analysis from the randomized controlled phase II trial (RCT) of tivantinib in second-line hepatocellular carcinoma (HCC). 2016 Gastrointestinal Cancers Symposium. (San Francisco, January 21-23, 2016). J Clin Oncol 34, 2016 (suppl 4S; abstr 197).

37 Rimassa L, Porta C, Borbath I, Daniele B, Finn RS, Raoul JL, Schwartz LH, He AR, Trojan J, Radosavljevic MP, Abbadessa G, Goldberg T, Santoro A, Bruix J: Tivantinib in MET-high hepatocellular carcinoma patients and the ongoing phase III clinical trial. Hepat Oncol 2014;1:181-188.

38 Abou-Alfa, GK, et al. Phase III randomized study of second line ADI-peg 20 (A) plus best supportive care versus placebo (P) plus best supportive care in patients (pts) with advanced hepatocellular carcinoma (HCC). J Clin Oncol 2016;34 (suppl; abstr 4017).

39 Bruix, J. et al, World GI Oncology Congress, Barcelona 2016.

40 Kokudo N, Hasegawa K, Akahane M, Igaki H, Isumi N, Ichida T, Umemoto S, Kaneko S, Kawasaki S, Ku Y, Kudo M, Kubo S, Takayama T, Tateishi R, Fukuda T, Matsui O, Matsuyama Y, Murakami T, Arii S, Okazaki M, Makuuchi M: Evidence-based clinical practice guidelines for hepatocellular carcinoma: the Japan Society of Hepatology 2013 update (3rd JSH-HCC Guidelines). Hepatol Res 2015 (in press). 